\title{
A DIAGNOSIC METHOD FOR ASSESSING REGIONAL VARIATIONS IN CROP YIELD
}

\author{
T. Doré \\ Laboratoire d'Agronomie INRA/INA Paris-Grignon, 16 rue C. Bernard, 75231 Paris Cedex, France \\ M. Sebillotte * \\ $\&$ \\ J.M. Meynard \\ Laboratoire d'Agronomie INRA/INA Paris-Grignon, 78850 Thiverval-Grignon, France
}

Key-words: Agronomic diagnosis, crop yield variations, cropping system

\begin{abstract}
The diagnosis of agronomic problems in cropping systems is often limited to surveys among farmers, in which they are asked the problems they encounter. This paper describes an alternative method of diagnosis to understand the variations in crop yield on a regional scale. It is based on multiannual on-farm surveys, where data are collected on the cropping system, environment and crop yield build-up. The different steps of the method - choice of study area and of farmers' fields, choice of methods, design of further experiments, and diagnosis itself, plus the way they are linked to each other, are developed and discussed.
\end{abstract}

* Present address: INRA, DADP, 147 rue de l'université, 75338 Paris Cedex 07, France 


\section{INTRODUCTION}

Zandstra (1979) has clarified the relationships and differences between farming systems research, agronomic research whose objective is to increase the resource-use efficiency of a given crop, and cropping system research whose objective is to increase the efficiency of use of a given quality and quantity of physical resources in crop production, which is the topic of this paper. He proposed specific methods for cropping system research and Zandstra et al. (1981) formalised an approach based on these methods, emphasizing the advantage of situating the major part of the work in farmers' fields. As for Farming System Research, the approach includes the four stages of diagnosis, design, test and extension. The first step of diagnosis is crucial if the whole approach is to succeed. Indeed Fujisaka (1994) analysed the failure of farmers to adopt innovations and incriminated not only the nature of the innovation itself and the way it was presented to farmers, but also in some situations the diagnosis which identified the problems leading to the innovation. Although some authors, such as Byerlee et al. (1991), insist on the value of including agronomic observations in the diagnostic stage of FSR programs, the way the cropping system problems are identified in these programs is often transcribed from the way the farming systems problems are identified, i.e. simply by verbal diagnosis: following the description of the study area, a survey is carried out among the farmers (Zandstra et al., 1981; Pillot, 1988). Cropping system problems which are pointed out as improvement-relevant are thus those which are indicated by farmers and discussed with them (Fujisaka, 1991). When measurements are done on farmers' fields, they are mainly used for more accurate assessment of crop performance and as a support for discussion with the farmers (Fujisaka, 1991). As farmers may not have all the information and agronomic knowledge needed to clearly identify and formulate a cropping system problem, this paper discusses an alternative analysing method for cropping system results, which aims at establishing a hierarchy of the problems to be solved. This method is consistent with the approach of Zandstra et al. (1981), and may easily be integrated in a FSRD program (Crozat \& Chitapong, 1988). It is based on results obtained under different soil and climatic conditions (temperate, semi-arid or tropical areas), and in different economic environments (industrialised countries and 
developing countries) (Manichon \& Sebillotte, 1973; Sebillotte et al., 1978; Boiffin et al., 1981; Jouve, 1984; Crozat et al., 1986; Diouf, 1990; Doré, 1992; Aubry et al., 1994; Leterme et al., 1994; Clermont-Dauphin, 1995). A few examples of findings are:

a. Farmers in an area of France (Champagne crayeuse), which had been cultivated for three decades, thought that the between-years variations in wheat yield were due to a decrease in the soil organic matter content. Sebillotte et al. (1978), Meynard et al. (1981) and Boiffin et al. (1982) showed that this was wrong, and identified the crucial roles of the slow soil warming in spring on tillering and yield build-up, and the strong influence of frequent soil compaction due to traffic during the sowing period, as major sources of yield variations.

b. The rice limiting factors in the dry seeded rice cultivation in the Sathing Phra area (Thailland) were believed by farmers to include poor land preparation and wild rice infestation as major problems. But Crozat et al. (1986) and Crozat \& Chitapong (1988) used the diagnosic method to show that the main limiting factors were plant losses due to rapid submersion and/or rat and crab damage, and the effect of the paddy water level on tilling.

c. The role of nitrogen nutrition on pea yield build-up in the Seine-et-Marne district in France was pointed out by Doré (1992). Bad nitrogen nutrition was encountered in fields where the seedbed soil structure and insect attacks were not completely controlled, but these factors were not considered to be very important by the farmers. The role of the sowing period in yield variations was pointed out in this study.

d. Lastly Clermont-Dauphin (1995) showed the effects of soil-borne diseases due to crop successions and low levels of soil minerals on bean yields in Haïti. This second source of variation, due to the well-known low soil fertility aggravated by high rainfalls leading to leaching of nitrogen and cations, was known by farmers, but the first problem of diseases was not recognised by the farmers or by the local agronomists. 


\section{A SPECIFIC VIEW ON CROP YIELD BUILD-UP}

This section briefly describes the hypotheses on which the method is based, to make it easier to understand the stages of the method and their relationships

\section{The aim of diagnosis}

This method deals with cropping systems. For a long time now, and especially since environmental considerations have intensified and the concept of farming systems sustainability has appeared (Hatfield \& Karlen, 1994; Barnett et al., 1995), the evaluation of cropping systems has not been restricted to the yield levels of the cropping system species. The other effects of cropping systems within and beyond the fields have also been taken into account. But crop yields are still a major parameter for evaluating the cropping system. The diagnostic framework presented here was first developed to deal with problems of environmental changes under some cropping systems. The first studies using this method in France (Manichon \& Sebillotte, 1973; Sebillotte et al., 1978) were motivated by problems of soil fertility that were pointed out by farmers whose cropping systems were continuous maize monoculture or wheat/spring crop successions on thin soils. It has since been enlarged to cover a wide range of questions and situations. The choice of focusing on crop production variations in the proposed framework provides an overall synthetic evaluation of the cropping systems, at the apparent expense of a more comprehensive approach to the environment.

Diagnosis is made on a sample of fields in a studied area. For a given crop, the objective is to identify the cultivation techniques and the environmental characteristics not affected by crop management that are responsible for yield variations. Crop management includes the choice of variety and the methods of crop establishment, fertilisation, pest management (weeds, insects, diseases) and harvest (component technology) for the studied crop, and crop succession. Environment is defined according to Zandstra (1979) as “ [...] such land and climate-related variables as available rainfall and irrigation, textural profile of the soil, phreatic level [...]". As the diagnosis here is solely agronomic, the environment does not 
include "the availability of such resources as power, labour and cash" (Zandstra, 1979); but we consider that these parameters influence the way crop management occurs for each field. Both crop management and environnement include many features, and this is the major difficulty for crop yield diagnosis. For example, a given field with high yield might be sown early with a heat-sensitive variety after deep tillage and without irrigation, whereas another field with low yield in the same environment might be sown later with a non-sensitive variety and with zero-tillage, and be heavily irrigated. To which of the features of crop management (sowing date, variety, tillage, irrigation level) should be attributed these differences in yield? The proposed method is designed to identify the characteristics of crop environment and crop management (and their interactions) that are responsible for these differences, whenever the differences in yield among farmers' fields requires

If the objective specified above is to have any meaning in the context of cropping system improvement, variations in yield in the sample of fields on which the diagnosis is based must not be due solely to differences in the environment. Few changes in cropping systems will be relevant if differences due to crop management are negligible compared to those caused by large environmental differences, such as large differences in rainfall in non-irrigated areas, or in soil salinity. As a consequence, the study area in which a crop yield diagnosis is performed should not be too large. Intuition and experience show that variations in climate and soil increase beyond some hundred $\mathrm{km}^{2}$ (which generally corresponds to a group of villages, or a FRSD operation, or a watershed), and that the proposed method is no longer effective on such a scale.

\section{Relationships between yield build-up and crop management}

The proposed diagnosic method is based on a systems representation of the relationships between cultivation techniques and yield build-up developed by Sebillotte $(1974,1978 a, 1995)$ and summarised in figure 1. It points out: 
i - the rejection of any permanent relationship between cultivation technique and yield. This is partly due to the huge effect of the climate on the cultivation technique result. But it is also useful to consider that cultivation techniques rarely affect yield build-up directly. They generally alter environmental parameters, which are constantly changing; we prefer to describe these changes as «environment states ». Whereas Zandstra (1979) defined environment factors as those influencing crop production but not influenced by cultivation techniques, the environment states include physical (such as soil structure), chemical (such as amounts of available nitrogen), and biological (such as real pest attacks) components of the field which are modified by these cultivation techniques.

ii - the existence of strong interactions between cultivation techniques. They are due to the fact that each cultivation technique modifies more than one aspect of the environment state (for example not only soil structure but also weed and pest dynamics and mineral and organic matter distribution in soil are modified by soil tillage); and conversely one environment state is the result of several cultivation techniques (for example weed infestations depend not only on weed management but also on crop density, soil tillage, etc.).

iii - the need to consider crop growth and development as a dynamic process influenced by changes in environment state. This point is also the preoccupation of authors designing integrated crop models (Cf. for example references in Whisler et al., 1986, and McCown et al., 1996).

This representation optimises the use of agronomic knowledge. This knowledge concerns both yield build-up under different environmental conditions, and the changes in the environmental state that occur when cultivation techniques are used in different conditions. This shows the causal relationships between cultivation techniques and yield build-up, on which the diagnosis itself is based. 


\section{THE DIAGNOSIC METHOD}

Making a diagnosis on crop yield variations therefore involves in analysing crop yield build-up on a field network to describe the relationship between crop management, environment and yield for each field using the relationships shown in figure 1, and then to make an overall regional review based on individual field results. This review is a hierarchy of the features of crop management and environment responsible for the observed variations in yield. The diagnosis follows the general framework summarised in figure 2. Diagnosis is repeated for several seasons in the same area to explore the year-to-year variations due to climate.

\section{Choice of a device}

The relevance of the diagnosis depends greatly on the quality of the initial lay-out. The choice of the farmers' field sample is based on three criteria: (i) environment variations and (ii) crop management variations in the study area, and (iii) published data on crop susceptibility to differences in environment and crop management. Data on environment variations is taken from available maps on soil and climate characteristics and often from the personal knowledge of farmers and advisers. Special attention is paid to those environment features that are known to damage the studied crop, such as extreme temperatures or soil excess water. Different types of environment that may be encountered in the area are usually distinguished by simple indicators which allow each field in the area to be easily assigned an environment type. Thus Boiffin et al. (1982) defined 11 environment types in the area they studied. They were based on the nature and depth of the different soil layers, as the other characteristics of the environment varied little, and each field of the sample was attached to one of these types ${ }^{1}$. Variations in the cropping systems usually adopted by farmers is also assessed by a preliminary verbal survey of farmers and advisers. After these data have been recorded, the rule for choosing the sample of

1 To simplify matters, variations in the environment within each field are not considered here. If such heterogeneity of the environment in a field is high, the whole set of observations is carried out in an homogeneous zone, representative of the most common environment type in the field. 
sites (the farmers' fields managed by farmers themselves) is then selected so as to represent, as far as possible, these variations in both environment and crop management (Sebillotte, 1978b).

Hence, in the study of Diouf (1990) on the variations in millet yield in the Sob area of Senegal, two soil types were identified, and the main differences in cropping systems according to the preliminary survey were in field type («home fields » close to houses $v s$. « bush fields » at some distance), thinning date, thinning intensity, penning practices during the dry season, manure fertilisation, and weeding frequency. Variations in all these criteria except hoeing, which occured too late in the crop cycle, were taken into account in the sample choice.

Hypotheses on the main sources of variations in crop yield may generally be made $a$ priori after the preliminary survey. Boiffin et al. (1981) assumed, before the start of the diagnosis itself, that variations in nitrogen absorption and in soil type were mainly responsible for variations in the yield of winter wheat in an area of France. The farmers' fields were therefore chosen for the diagnosis by:

(i) including in the sample different situations of nitrogen nutrition, using differences in soil texture or in the preceding crop. Pairs of fields differing by only one factor were used as far as possible. These could be two parts of the same field, one part with the « terre rouge » soil type and one part with the «terre blanche » soil type, or one part with sugar beet as a preceding crop and one part with maïze. Using such pairs of fields makes it possible to come closer to the structure of an experimental design, while maintaining the diversity of farmers' field situations (Sebillotte, 1978b; Boiffin et al., 1981), and avoids difficulties in pointing out limiting factors due to correlations in fields characteristics.

(ii) including fields differing by other environment and crop management features, in order to assess their effects on crop yield.

Previous sections showed that a diagnosis can only be undertaken if the relationships in figure 1 may be understood. As the literature is rarely complete, it is often necessary to supplement initial knowledge of crop and environment state changes by specific experiments. Boiffin et al. (1981) found that the wheat yield build-up could only be analysed if there was accurate information on the nitrogen dynamics in the soil and crop on each farmer's field. This 
was possible only if the crop yield response to increasing rates of nitrogen fertilisation on all the different soil types of the study area was known. The general outline of such a response was known, and was not altered by soil differences, but there were differences in the precise values according to the soil type and to the soil structure within each soil type. Several experiments comparing fertilizer rates and splitting were therefore done over the three years in different environment conditions to enable diagnosis in the farmers fields. In the same study by Boiffin et al. (1981), experiments comparing the effect of different soil structure states on yield buildup were also done during the last year of the diagnosis, to check the results from the two first years. In some cases where there is little initial knowledge, such experiments may take a large part of the time and be an important stage in the diagnosis (see for example Latiri-Souki et al., 1992). Further experiments may also be useful to enlarge the range of environment states compared to those observed in farmers' fields: understanding what appears in such extreme situations makes it generally easier to understand farmers' real situations.

This approach limits the number of farmers fields to $20-40$ for each year, which is far fewer than the number generally used in crop surveys without or with very few agronomic observations (Byerlee et al., 1991; Fujisaka, 1991). Table 1 shows the main aspects of the design used by Boiffin et al. (1981).

\section{Choice of methods for agronomic observations on farmers' fields}

The accuracy of the diagnosis will depend on the precision with which differences in crop yield build-up are interpreted. Analysis of crop yield build-up requires knowledge of crop growth and development in potential conditions, and of the effects of the main limiting factors. A pattern representing the process of yield build-up (Sebillotte, 1978a, 1980; Fleury et al., 1982) may be used, and this makes it possible to understand crop growth and development during the whole crop cycle. Such a model shows all the characteristics on one crop (for example yield components) and on the environment states which must be recorded on each field in order to understand yield build-up in these fields (Boiffin et al., 1981). There are several tools available to make a diagnosis on the crop at a given time. Meynard and David (1992) reviewed the tools 
which might be used to identify the periods of crop failure. They include growth measurement, with identification of the date at which it becomes lower than potential growth assessed by a model, the analysis of yield components, the analysis of branching. Diagnosis tools for crop mineral nutrition are now used more and more, as are nitrogen nutrition index (Lemaire et al., 1989) and isotopic discrimination (Gede, 1992); they make it possible to identify problems in the essential physiological functions of the crops, and to identify the environment states responsible for these problems.

To understand the relationships between crop management, the environment and the environment states requires a description of crop management and environment for each field. This, in turn, demands a record of crop management and the cropping history for each of them. Records should be as precise as possible, and concern not only the tools used and the management dates, but also the conditions in which management is done : soil structure, for example, will not only depend on the type of tillage but also on the soil humidity during tillage. The environment in each field cannot be described only from soil and climate maps. The soil units used for mapping are generally based on the characteristics of soil formation, and they generally do not reflect differences in soil state changes due to climate and cultivation. But these are the differences that a soil classification useful for diagnosis must account for, and variations in permanent soil characteristics such as slope, soil texture, or water circulation in soil are important only if they lead to these differences. The same approach must be adopted to describe climate in the study area. Table 2 shows the agronomic observations on crop, environment states, crop management and environment used in a study on pea crop yield variations in France (Doré, 1992).

\section{Carrying out the diagnosis}

\section{$\underline{\text { First diagnosis stage: yield build-up analysis on farmers' fields }}$}

This stage establishes the links between yield and environment states (soil structure, pest attacks, soil water content...) on the farmers' network of fields. Three procedures are used to establish causal relations, not only correlations: 
- using pairs of fields which differ by only one characteristic of crop management or environment in the field network (see above),

- using models representing the process of build-up in order to understand when and in what physiological way production was decreased. Identifying the date or the period during which differences occurred between fields is particularly useful: if we know at which time in the crop cycle production failed compared to the potential yield, we reduce the number of possible limiting conditions - which need to be identified because only the factors and environment states which have a real effect during this period are concerned. Figure 3 shows the results obtained by Doré (1992) on the yield of pea crops in the Seine-et-Marne district (France): the close relationship between grain number and yield on farmers' fields shows that the main limiting factors appeared during grain formation, and not during the seed filling.

- using comparisons of the records made on the whole set of fields in the network. The aim of these comparisons is first to test hypotheses made on each of the fields. This is absolutely necessary, because even if previous knowledge of crop yield build-up is used to understand what occurred on each field, the limiting factors in each of these fields will rarely be unequivocally identified. Only comparison with the results obtained in the other fields of the sample, which makes it possible to prospect a wide range of values for the suspected limiting factors, generally provides a final response. Doré (1992) give an example of this use of between-field comparison to demonstrate the influence of nitrogen nutrition on seed number and yield in pea crops (figure 4). Poor nitrogen nutrition was mainly due to cloddy or crusty seedbeds and to attacks by Sitona lineatus.

This first stage of diagnosis leads each year to a hierarchy of the environment states which are responsible for differences in farmers' fields crop yield. Aubry et al. (1994) examined durum wheat in a semi-arid area of Tunisia and showed that soil structure around seeds and weed infestations had major effects during the first year of the diagnosis (with high 
rainfall), while soil water content after sowing and soil structure in the ploughed layer were important during the second year (with low rainfall).

Second diagnosis stage: identifying aspects of crop management and environment $\underline{\text { responsible for differences in environment states }}$

The environment states which were identified as responsible for differences in crop yield build-up during the first diagnosis stage (for example bad soil structure, a deficiency in a mineral, a water stress, or a serious pest attack), become variables to be understood in the second stage. Changes in physical, chemical and biological environment states are the result of interactions between the environment and crop management. Sources of favourable or unfavourable environment states (which the subsequent design of improved cropping systems will try to avoid) are identified using previous knowledge of the effects of cultivation techniques on the environment state. As an example, Doré \& Meynard (1995) in the study cited above used knowledge of the behaviour of Sitona lineatus to show the influence of the pea crop sowing date on the intensity of Sitona attacks. There are some models of environment state changes, which may be used to understand what occurs in farmers' fields (for example Manichon, 1982; Stockle et al., 1994). Some final results for this second diagnosis stage are shown in table 3 (Leterme et al., 1994) for wheat crops in an area of France. The major environment states responsible for differences in crop yield and identified after the first diagnosis stage were problems during meiosis, drought stress at flowering, drought stress at stem elongation, stem diseases, root diseases, and soil structure in the ploughed layer. They were explained in the second diagnosis stage by differences in the amounts of stones in the fields, total rainfall and its distribution throughout the year (environment parameters) and sowing date and nature of preceding crop (crop management parameters).

\section{$\underline{\text { Synthesis }}$}

Each year, after each of these two stages has been carried out, the environment and crop management situations can be linked to risks of yield decrease. Such a diagnosis is conducted over several consecutive years to operate under different climate characteristics, and leads to a 
more general hierarchy of crop yield limiting factors. This hierarchy may be enlarged and more precisely established using an analysis of climate variations over a longer period. The observations and results obtained one year may also reveal imperfections in the choice of field or a lack of the knowledge needed to understand yield build-up in farmers' fields. Improvements may thus be made from one year to another during the study.

\section{DISCUSSION}

This diagnosic method is based on agronomic observations in farmers' fields. Comparisons with the FSR approach and traditional agronomic research show that it provides a new framework. The farmer's field has an important place in FRS programs, but it is generally limited to the design, test and extension stages occurring after the diagnosis stage. When it is present in the diagnosis stage (Fusijaka, 1991), its role is minor compared to the role of interviews. To give place and sense to the farmer's field as an object of study is a methodological innovation. Most standard agronomic research takes place on experimental farms. Sebillotte $(1974,1978 b)$ showed that this sort of research was not sufficient to improve cropping systems, particularly because variations in farmers' practices and in their own innovations could not be easily reproduced in experimental farms.

Apart from the studies coming under the described method, there are few references to studies using farmers' fields for diagnosis. Durrant (1988) performed such a diagnosis in farmers' fields in a comparable manner, but limiting the target of the diagnosis to one short part of a crop cycle, i.e. emergence of sugar beet. In the other references reporting studies conducted in farmers' fields (for example Hardwick et al., 1979; Burleigh et al., 1991; Shafiq et al., 1993), crop yields were rather directly correlated to cropping systems and environment parameters, with only very few or, in some cases, no observations on crops and changes in environment state. This correlative method involves extrapolating classical procedures used in agronomic research in experimental stations, where the effects of experimental treatments (i.e. different, often close, values of crop management) are compared, all the other parameters being fixed. As soon as this last condition is no longer true, as in a network of farmers' fields, 
the observed correlation no longer represents causal relations between yield and crop management. This points out another original aspect of the present method, which is to try as far as possible to understand variations in crop yield between fields by using available agronomic knowledge through agronomic observations. This analysis of crop yield differences makes it possible to identify the parameters of crop management and environment which are responsible for these differences, with very little risk of error.

As a consequence diagnosis itself, and especially its first stage, cannot be carried out if substantial agronomic knowledge is not available. What we call «models representing the process of build-up » are well represented by formal crop models. Crop models which simulate potential crop growth and development under optimal conditions (for example Van Keulen et De Miliano, 1984; Hearn 1994; Guttíerrez et al., 1994; Moen et al., 1994; Nagarajan et al., 1994) may be especially useful. If inputs can be recorded on farmers' fields, it becomes possible to simulate potential crop growth and development on each field and to compare the simulated results to the real crop growth on the fields. The observed differences may be used to identify the date when a limiting factor occurred (Sebillotte, 1989). Such an approach was used by Dejoux (1993) to identify the main limiting factors under integrated and ecological agriculture in the Netherlands, and by Pons and Lafon (1991) to identify mineral nutrition problems in grasslands in France. An important condition for crop model use is that the inputs and intermediate variables remain easily accessible, as the study takes place in large number of farmers' fields.

The method described here includes not only the diagnosis stage itself, with substantial work for data recording and processing, but also preliminary work for choosing and characterising the field network, and carrying out further experiments. The total amount of work is thus considerable, and Pillot (1988) pointed out that this, as well as the correlated slowness, heaviness and high cost were the most important drawbacks of the method, especially if it is compared to other methods using only verbal diagnosis. This cost should, however, be offset by the more effective diagnosis (Byerlee et al., 1991). This method also provides substantial information on cropping systems after the diagnosis stage, which allows time to be 
saved during the following stages of design, test and extension of the innovation (Crozat \& Chitapong, 1988).

\section{CONCLUSION}

This method of crop yield diagnosis has been tested and improved over more than 20 years and under a wide range of agricultural conditions. It is based on agronomic observations and it seems to be a possible alternative method to those currently used to identify sources of crop yield variations and to define further aims in cropping systems improvement, either expert opinions which are widely used to determine research priorities but rarely leading to a consensus (Smith, 1994), or farmers' own opinions. This method was gradually built on the basis of concrete experience, and it has been designed with the ongoing intention of preserving the ability to include such a diagnosis in $R \& D$ programs, and the possibility of using increasing agronomic knowledge. Its use to answer other questions of diagnosis, such as crop quality or effects of cropping systems on natural resources, is presently being tested. 


\section{ACKNOWLEDGEMENTS}

We thank all our colleagues (especially from the laboratoire d'agronomie INRA/INA ParisGrignon) who contributed to the building of this diagnosis method, with their active work or with their ideas, during diagnosis activities they carried out in different areas in the world. We also thank C. Young and O. Parkes for revising the English. We are grateful to Elsevier Publications for permission to use table 3. 


\section{REFERENCES}

Aubry, C., Latiri-Souki, K., Doré, T. \& Griner, C. (1994). Diagnostic des facteurs limitants du rendement du blé dur en parcelles d'agriculteurs dans une petite région du semi-aride en Tunisie. agronomie, 14(4), 213-227.

Barnett, V., Payne R. \& Steiner, R. (1995). Agricultural sustainability. John Wiley and Sons, Chichester.

Boiffin, J., Caneill, J., Meynard, J.M. \& Sebillotte, M. (1981). Elaboration du rendement et fertilisation azotée du blé d'hiver en Champagne crayeuse. I.- Protocole et méthode d'étude d'un problème technique régional. agronomie, 1(7), 549-558.

Boiffin, J., Meynard, J.M., Sebillotte, M. \& Caneill, J. (1982). Elaboration du rendement et fertilisation azotée du blé d'hiver en Champagne crayeuse. III. Influence des variations pédologiques; conséquences pour la conduite de la culture. agronomie, 2(5), 417-428.

Burleigh, J.R., Yamoah, C.F., Regas, J.L. \& Eylands, V.J. (1991). Analysis of factors related to wheat yield on farm fields in the Bureruka highlands of Rwanda. Agron. J., 83, 625-631.

Byerlee, D., Triomphe, B. \& Sebillotte, M. (1991). Integrating agronomic and economic perspectives into the diagnostic stage of on-farm research. Expl. Agric., 27, 95-114.

Clermont-Dauphin, C. (1995). Fertilisation minérale d'une association haricot-maïs en zone tropicale humide. Thèse de Doctorat de l'INA-PG, Paris.

Crozat, Y. \& Chitapong, P. (1988). The on-farm agronomical survey: a tool for grading limiting factors of a crop and designing new technologies. In "Farming systems research and development in Thailand. Illustrated methodological considerations and recent advances", GRET/Prince of Songkla University, France/Thailand, 85-108.

Crozat, Y., Sitticharoenchai, A., Kaewvongsri, P., Pronpinatepong, S. \& Chitapong, P. (1986). The improvement of rice cultivation in Sathing Phra area, Songkla lake basin: illustration of a methodology based on the yield differentiation between farmers' plots. Thai-French farming systems research project, Faculty of natural resources, Publication $n^{\circ} 6$, Prince of Songkla University, Songkhla. 
Dejoux, J.F. (1993). Diagnostic agronomique sur le blé dans des systèmes de culture intégrés et écologiques aux Pays-Bas. Mémoire d'Ingénieur, INA-PG, Paris.

Diouf, M. (1990). Analyse de l'élaboration du rendement du mil (Pennisetum typhoides Stapf et Hubb.). Mise au point d'une méthode de diagnostic en parcelles paysannes. Thèse de Doctorat de l'INA-PG, Paris.

Doré, T. (1992). Analyse, par voie d'enquête, de la variabilité des rendements et des effets précédent du pois protéagineux de printemps (Pisum sativum L.). Thèse de Doctorat de l'INA-PG, Paris.

Doré, T., Meynard, J. M. (1995). On-farm approach of attacks by the pea weevil (Sitona lineatus L.; Col., Curculionidae) and the resulting damage to pea (Pisum sativum L.) crops. $J$. appl. Ent., 119, 49-54.

Durrant, M.J. (1988). A survey of seedling establishment in sugar-beet crops in 1980 and 1981. Ann. appl. Biol., 113, 347-355.

Fleury, A., Masle, J. \& Sebillotte, M. (1982). L'analyse de l'élaboration du rendement, outil de jugement du milieu. Bull. Tech. Inf., 370-372, 357-362.

Fujisaka, S. (1991). A set of farmer-based diagnostic methods for setting post «green revolution » rice research priorities. Agricultural systems, 36, 191-206.

Fujisaka, S. (1994). Learning from six reasons why farmers do not adopt innovations intended to improve sustainability of upland agriculture. Agricultural Systems, 46(4), 409-425.

Gede Wibawa (1992). Approche par enquête et expérimentation de l'effet de l'état structural du sol sur la nutrition azotée et l'élaboration du rendement de l'orge de brasserie. Thèse de Doctorat de l'INA-PG, Paris.

Guttíerrez, A.P., Marrot, E.J., Cure, J.L. \& Wagner Ribble, C.S. (1994). A model of bean (Phaseolus vulgaris L.) growth types. III. Factors affecting yield. Agricultural Systems, 44(1), 35-64.

Hardwick, R.C., Andrews, D.J., Hole, C.C. \& Salter, P.J. (1979). Variability in number of pods and yield in commercial crops of vining peas (Pisum sativum L.). J. Agric. Sci. Camb., 92 , $675-681$. 
Hatfield, J.L., Karlen, D.L. (1994). Sustainable agriculture systems. Lewis Publishers, Boca Raton.

Hearn, A.B. (1994). Ozcot: a simulation model for cotton crop management. Agricultural Systems, 44(3), 257-299.

Jouve, P. (1984). Le diagnostic agronomique: préalable aux opérations de RechercheDéveloppement. Cahiers de la Recherche-Développement, 3/4, 67-76.

Latiri-Souki, K., Aubry, C., Doré, T. \& Sebillotte, M. (1992). Elaboration du rendement du blé dur en conditions semi-arides en Tunisie: relations entre composantes du rendement sous différents régimes de nutrition azotée et hydrique. agronomie, 12(1), 31-43.

Lemaire, G., Gastal, F. \& Salette, J. (1989). Analysis of the effect of N nutrition on dry matter yield of a sward by reference to potential yield and optimum $\mathrm{N}$ content. In "Proc. 16th Int. Grassland Congress", Nice, France, 179-180.

Leterme, P., Manichon, H. \& Roger-Estrade, J. (1994). Analyse intégrée des rendements du blé tendre et de leurs causes de variation dans un réseau de parcelles d'agriculteurs du Thymerais. agronomie, 14(6), 341-361.

Manichon, H. (1982). Influence des systèmes de culture sur le profil cultural: élaboration d'une méthode de diagnostic basée sur l'observation morphologique. Thèse de DocteurIngénieur, INA-PG, Paris.

Manichon, H. \& Sebillotte, M. (1973). Etude de la monoculture du maïs. Résultats d'une enquête agronomique dans les régions de Garlin et de Navarrenx (P.A.). Rapport Chaire d'Agriculture, INA-PG, Paris.

McCown, R.L., Hammer, G.L., Hargreaves, J.N.G., Holzworth, D.P. \& Freebairn (1996). APSIM: a novel software system for model development, model testing and simulation in agricultural systems research. Agricultural systems, 50(3), 255-271.

Meynard, J.M. \& David, G. (1992). Diagnostic sur l'élaboration du rendement des cultures. Cahiers Agriculture, 1, 9-19.

Meynard, J.M., Boiffin, J., Caneill, J. \& Sebillotte, M. (1989). Elaboration du rendement et fertilisation azotée du blé d'hiver en Champagne crayeuse. II. Types de réponse à la fumure azotée et application de la méthode du bilan prévisionnel. Agronomie, 1(9), 795-806. 
Moen, T.N., Kaiser, H.M. \& Riha, S.J. (1994). Regional yield estimation using a crop simulation model: concepts, methods, and validation. Agricultural Systems, 46(1), 79-92.

Nagarajan, K., O'Neill, R.J., Lowenber-Deboer, J. \& Edwards, C.R. (1994). Indiana soybean system model (ISSM): I. Crop model evaluation. Agricultural Systems, 43(4), 357-379.

Pillot, D. (1988). Francophone and anglophone farming systems research: similarities and differences. In "Farming systems research and development in Thailand. Illustrated methodological considerations and recent advances", GRET/Prince of Songkla University, France/Thailand, 3-24.

Pons, Y. \& Lafon, E. (1993). Comment déterminer les facteurs limitants d'une prairie au printemps? Cas des marais de l'Ouest. Fourrages, 125, 19-28.

Sebillotte, M. (1974). Agronomie et agriculture. Essai d'analyse des tâches de l'agronome. Cah. ORSTOM, Série Biologie, 24, 3-25.

Sebillotte, M. (1978a). Itinéraires techniques et évolution de la pensée agronomique. C.R. Acad. Agric. Fr., 11, 906-913.

Sebillotte, M. (1978b). La collecte des références et les progrès de la connaissance agronomique. In "Exigences nouvelles pour l'agriculture, les systèmes de culture pourrontils s'adapter?", J. Boiffin, P. Huet \& M. Sebillotte Eds, ADEPRINA/INA-PG, Paris, 466496.

Sebillotte, M. (1980). Analyse de l'élaboration du rendement du blé: un moyen pour résoudre les problèmes de cette culture. In "Wheat, technical monograph", Ciba-Geigy, Bâle, 25-32.

Sebillote, M. (1989). Approaches of the on-farm agronomist: illustrated methodological consideration. Kasetsart University, Thailand.

Sebillotte, M. (1995). Analysing farming and cropping systems and their effects. Some operative concepts. In «System studies in agriculture and rural development», J. Brossier, L. de Bonneval \& E. Landais Eds, INRA, Paris, 283-290.

Sebillotte, M., Boiffin, J., Caneill, J. \& Meynard, J.M. (1978). Sécheresse et fertilisation du blé d'hiver; essai d'analyse de situations au champ par l'étude des composantes du rendement. Bull. Assoc. fr. Etude Sol, 3, 197-214. 
Shafiq, M., Azeem, M. \& Longmire, J. (1993) - Diagnosing alternatives in conventional crop rotations: sunflowers as an alternative to wheat in the cotton-based cropping systems of Pakistan's Punjab. Agricultural Systems, 42(3), 245-264.

Smith, P.J. (1994). Identifying research priorities in developing countries. Agricultural Systems, 45(4), 455-468.

Stockle, C.O., Martin, S.A. \& Campbell, G.S. (1994). CropSyst, a cropping systems simulation model: water/nitrogen budgets and crop yield. Agricultural Systems, 46(3), 335-359.

Van Keulen, H. \& De Miliano, W.A.J. (1984). Potential wheat yields in Zambia - A simulation approach. Agricultural Systems, 14, 171-192.

Whisler, F.D., Acock, B., Baker, D.N., Fye, R.E., Hodges, H.F., Lambert, J.R., Lemmon, H.E., McKinion, J.M. \& Reddy,V. R. (1986). Crop simulation models in agronomic systems. Adv. Agron., 40, 141-208.

Zandstra, H.G. (1979). Cropping systems research for the asian rice farmer. Agricultural Systems, 4, 135-153.

Zandstra, H.G., Price, E.C., Litsinger, J.A. \& Morris, R.A. (1981). A methodology for on-farm cropping systems research. IRRI, Los Baños. 


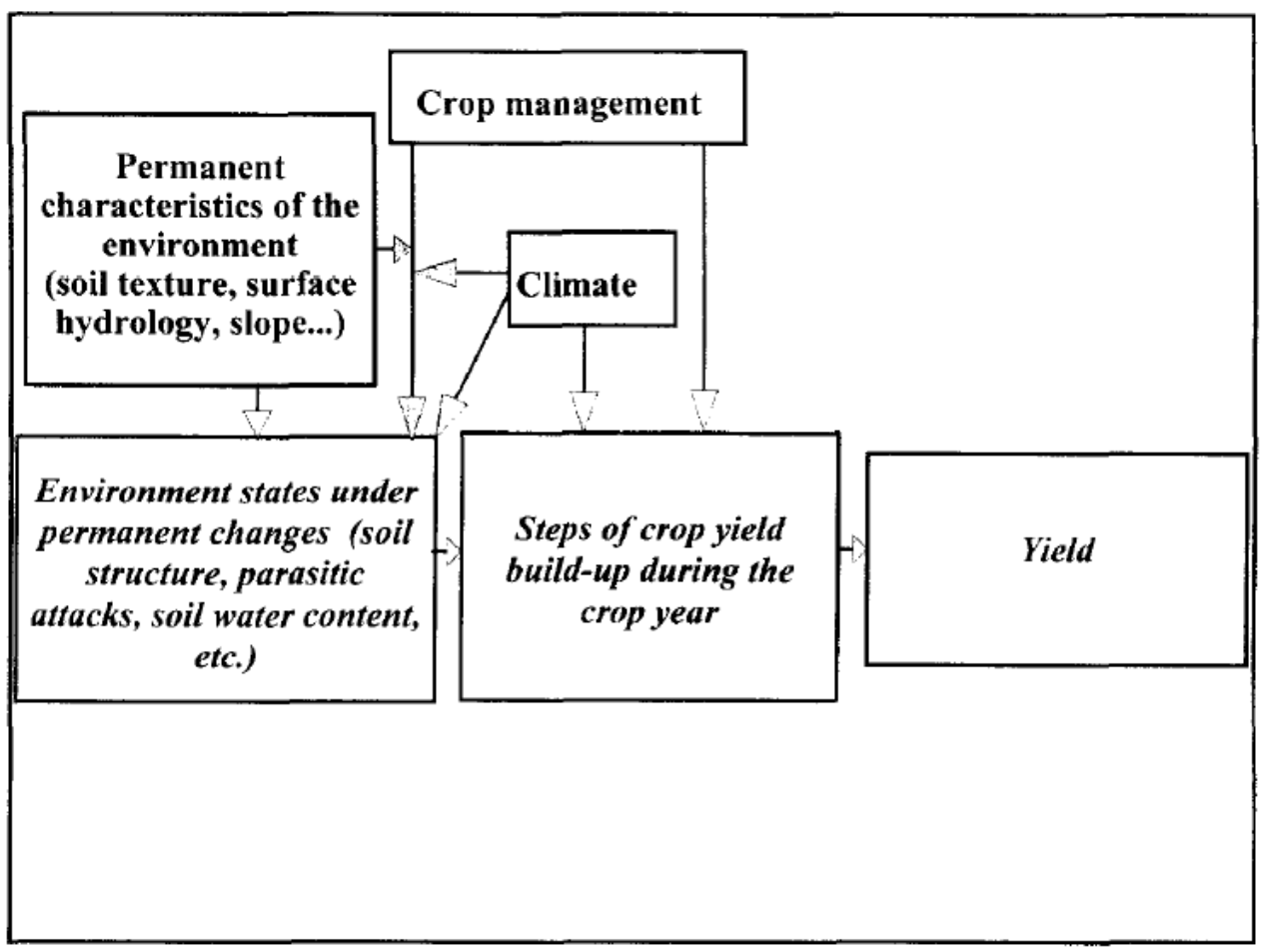

Fig. 1. Relationships between cropping systems and crop-yield elaboration.

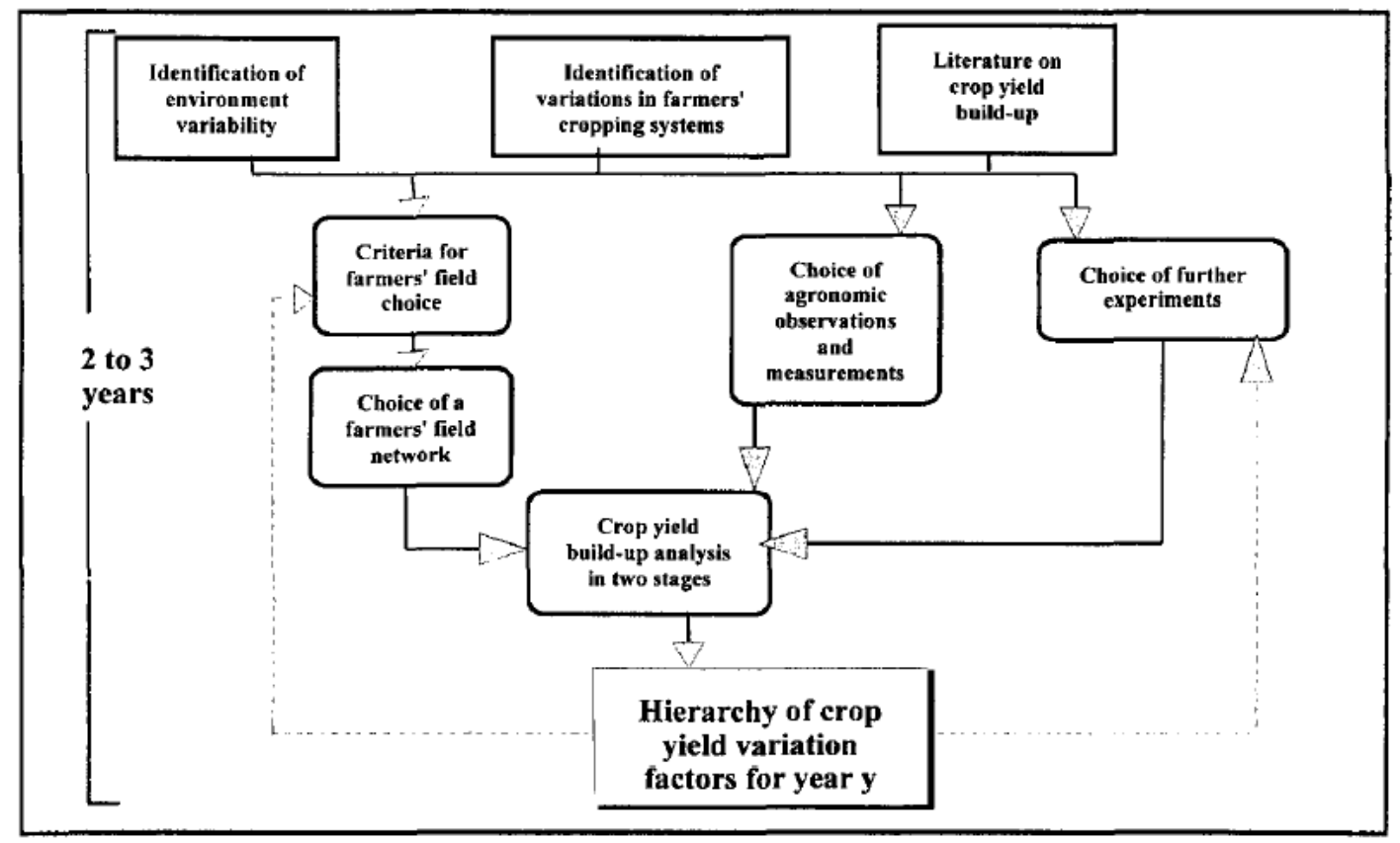

Fig. 2. Diagram showing the diagnostic method. 


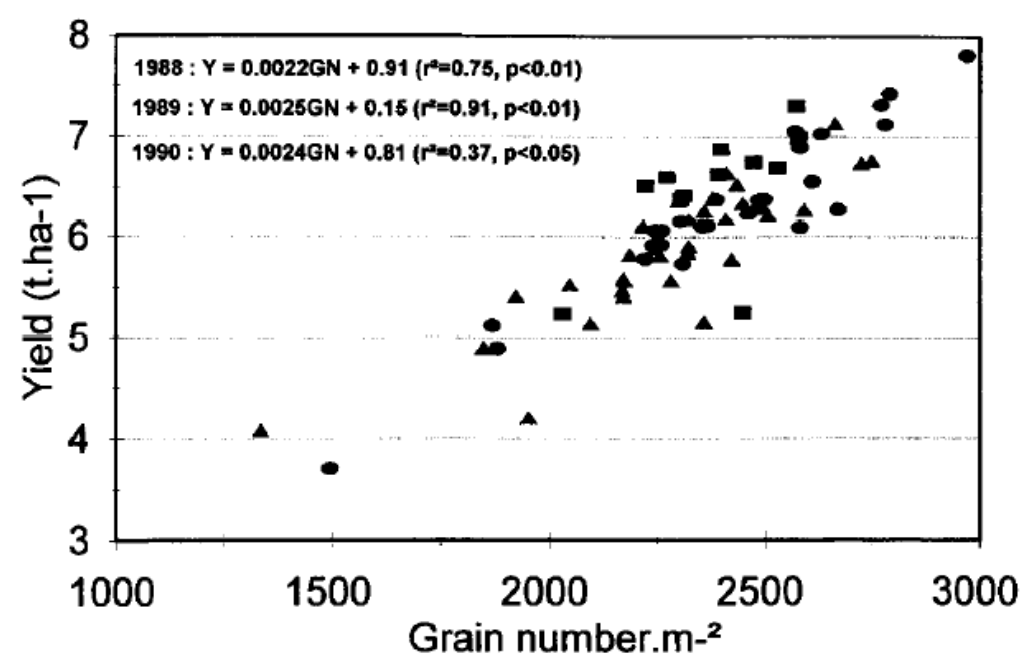

$\triangle 1988 \cdot 1989 \cdot 1990$

Fig. 3. Relationship between yield and grain number in a 3-year network of pea fields (Seineet-Marne district, France). This relationship was used to determine the period during which limiting factors occurred (from Doré, 1992).

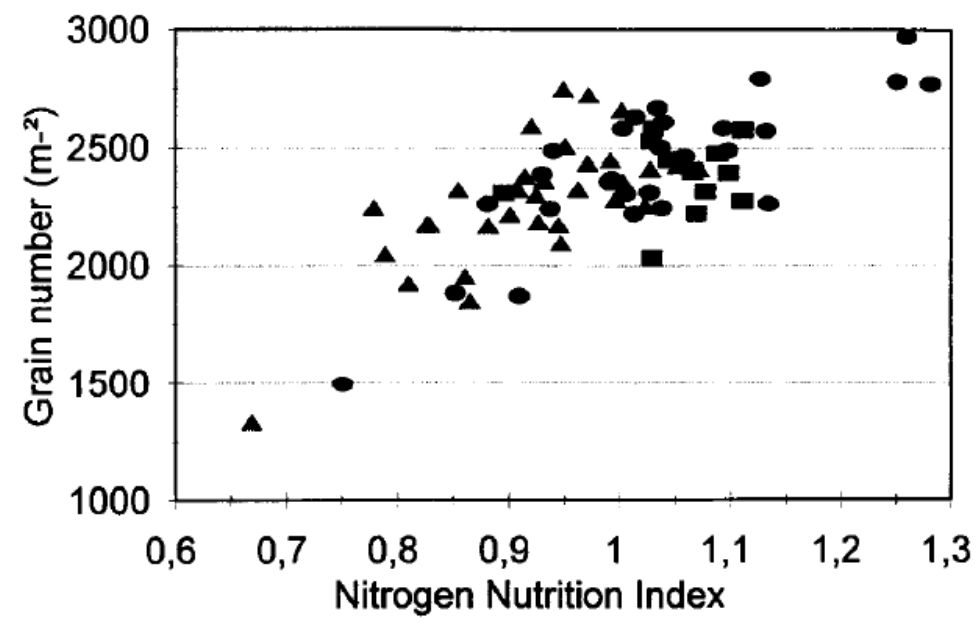

$\Delta 1988 \cdot 1989 \square 1990$

Fig. 4. Relationship between grain number and nitrogen nutrition, assessed by a nitrogen nutrition index, at the start of flowering in a 3-year network of pea fields (Seine-et-Marne district, France) (from Doré, 1992). 


\section{TABLE 1}

A design for the method of diagnosis (from Boiffin et al., 1981)

Farmers' fields $\quad$ * 24 in 1975,31 in 1976,19 in 1977. Choice on the basis of field
characteristics : soil type, preceding crop, wheat variety, bringing into
cultivation date...
$*$ including pairs of fields comparing the two major soil types («terre
rouge » $v s \ll$ terre blanche ») and the two major preceding crops
(sugar beet $v s$ maize)
Experiments
10 experiments during the three years, each one with 10 fertilizer
rates; All the experiments in «terre blanche » soil type, with the same
preceding crop and the same variety.


TABLE 2

The main measurements done on the fields used to diagnose variations in pea crop yield (from Doré, 1992)

\begin{tabular}{llll}
\hline \multicolumn{1}{c}{$\begin{array}{c}\text { Yield and parameters of } \\
\text { yield build-up }\end{array}$} & \multicolumn{1}{c}{$\begin{array}{c}\text { Characteristics of } \\
\text { environment states }\end{array}$} & Crop management characteristics & Environment characteristics \\
\hline - Plant number & - Seedbed soil structure & - Crop succession since 10 years & - Daily temperatures \\
- Number of branches at «3-4 leaf & $\begin{array}{l}\text { - Ploughed layer soil structure } \\
\text { stage » }\end{array}$ & - Tillage operations, date and & - Daily precipitation \\
- Flowering date & at three dates & - Soil texture \\
- Rooting depth at flowering & - Soil water content during the cycle & - Sowing depth and density & - Soil mineral content \\
- Aerial dry matter at flowering & - Soil nitrogen content & - Pesticide applications, rates and & - Soil depth \\
- Nodule dry matter per plant at & & application dates & - Soil organic matter content \\
flowering & & - P and K applications & \\
- Nitrogen content at flowering & & & \\
- Stem number at flowering & & & \\
- Pod number and grain number at & & & \\
harvest & & & \\
- Stem number at harvest & & & \\
- Yield & & & \\
\hline
\end{tabular}


TABLE 3

Results on the wheat crop in an area of France, for the second part of the diagnosis (from Leterme et al., 1994)

\begin{tabular}{|c|c|c|c|c|c|c|c|c|}
\hline & \multicolumn{4}{|c|}{ No-stony fields } & \multicolumn{4}{|c|}{ Stony fields } \\
\hline & \multicolumn{2}{|c|}{$\begin{array}{c}\text { Preceding crop is not } \\
\text { wheat }\end{array}$} & \multicolumn{2}{|c|}{$\begin{array}{c}\text { Preceding crop is } \\
\text { wheat }\end{array}$} & \multicolumn{2}{|c|}{$\begin{array}{c}\text { Preceding crop is not } \\
\text { wheat }\end{array}$} & \multicolumn{2}{|c|}{$\begin{array}{c}\text { Preceding crop is } \\
\text { wheat }\end{array}$} \\
\hline & $\begin{array}{c}\text { Sowing } \\
\text { date } \\
\text { before } \\
10 \\
\text { October }\end{array}$ & $\begin{array}{c}\text { Sowing } \\
\text { date after } \\
10 \\
\text { October }\end{array}$ & $\begin{array}{c}\text { Sowing } \\
\text { date } \\
\text { before } \\
10 \\
\text { October }\end{array}$ & $\begin{array}{c}\text { Sowing } \\
\text { date after } \\
10 \\
\text { October }\end{array}$ & $\begin{array}{c}\text { Sowing } \\
\text { date } \\
\text { before } \\
10 \\
\text { October }\end{array}$ & $\begin{array}{c}\text { Sowing } \\
\text { date after } \\
10 \\
\text { October }\end{array}$ & $\begin{array}{c}\text { Sowing } \\
\text { date } \\
\text { before } \\
10 \\
\text { October }\end{array}$ & $\begin{array}{c}\text { Sowing } \\
\text { date after } \\
10 \\
\text { October }\end{array}$ \\
\hline Problems during meiosis & - & & • & & • & • & • & • \\
\hline Drought stress at flowering & O & $\bullet$ & O & - & & $\bullet$ & & $\bullet$ \\
\hline Drought stress at stem elongation & & & & & $\bullet$ & $\bullet$ & $\bullet$ & $\bullet$ \\
\hline Stem diseases & • & $\bullet$ & $\bullet \bullet$ & $\bullet$ & & & & \\
\hline Root diseases & & & & $\bullet \bullet$ & $\bullet$ & $\bullet$ & & \\
\hline Soil structure in ploughed layer & & - & & & & $\bullet$ & & \\
\hline
\end{tabular}

No circle: no effect or very rare; O: sometimes observed in farmers’ fields; •: Observed on most farmers’ fields; • •: Observed on all or nearly all farmers’ fields 
